\title{
YÜZ TANIMA SISTEMLERİNDE DOĞRULUK PERFORMANSLARININ DEĞERLENDİRİLMESİ
}

\author{
Bekir AKSOY*
}

Isparta Uygulamalı Bilimler Üniversitesi, Teknoloji Fakültesi, Mekatronik Mühendisliği Bölümü, Isparta, Türkiye

\begin{tabular}{ll}
\hline Anahtar Kelimeler & Öz \\
\hline Görüntü İşleme, & Yüz tanıma sistemlerinin güvenlik açısından önemi son yıllarda oldukça artmıştır. \\
Yüz Tanıma, & Çalışmada, Isparta Uygulamalı Bilimler Üniversitesi Teknoloji Fakültesindeki \\
LDA Algoritması, & gönüllü ögrenci ve öğretim üyelerinden oluşan 41 kişiye ait ön, yan, üst ve alt yüz \\
PCA ve SVD Algoritması, & görüntüleri alınarak LDA, LBP ve PCA ile SVD yüz tanıma algoritmaları uygulanarak \\
LBP Algoritması. & her birine ait model elde edilmiştir. Elde edilen modeller test yüz görüntüleri \\
& üzerinde sinıflandırılarak, RMSE ve MAPE performans ölçüt kriterlerine göre \\
& değerlendirilerek ön ve yan yüz tanıma sisteminde PCA ve SVD algoritması, üst ve \\
& alt yüz tanıma sisteminde ise LBP Algoritmasının en iyi sonucu verdiği tespit \\
& edilmiștir.
\end{tabular}

\section{EVALUATION OF ACCURACY PERFORMANCE IN FACE RECOGNITION SYSTEMS}

Keywords
Image Processing,
Face Recognition,
LDA Algorithm,
PCA and SVD Algorithm,
LBP Algorithm.

LBP Algorithm.

\begin{abstract}
The importance of face recognition systems has increased in recent years. In this study, front, side, upper and lower facial images of 41 people consisting of volunteer students and faculty members from Isparta University of Applied Sciences were taken and LDA, LBP-PCA and SVD facial recognition algorithms were applied and their model was obtained. The obtained models were classified on the test face images and evaluated according to the RMSE and MAPE performance criteria. In the front face and side face recognition system, PCA and SVD algorithm, in the upper and lower face recognition system LBP algorithm were found to give the best results.
\end{abstract}

Alıntı / Cite

Aksoy, B., (2019). Yüz Tanıma Sistemlerinde Doğruluk Performanslarının Değerlendirilmesi, Mühendislik Bilimleri ve Tasarım Dergisi, 7(4), 835-842.

Yazar Kimliği / Author ID (ORCID Number)

B. Aksoy, 0000000180529411

\begin{tabular}{|l|l|}
\hline Makale Süreci / Article Process \\
\hline Başvuru Tarihi / Submission Date & 02.05 .2019 \\
Revizyon Tarihi / Revision Date & 30.05 .2019 \\
Kabul Tarihi / Accepted Date & 12.06 .2019 \\
Yayım Tarihi / Published Date & 19.12 .2019 \\
\hline
\end{tabular}

\section{Giriş}

Yüz tanıma, önemli biyometri tekniklerden birisidir. Görüntü ișleme, bilgisayarlı görü, güvenlik gibi farklı bilim dalları kapsamaktadır (Becerra vd., 2019). Bu alanlardan güvenlik son yıllarda uluslararası bir sorun haline gelmiştir. Bu sorunu çözebilmek için farklı veri ișleme teknikleri kullanılmaktadır. Biyometri kullanılan tekniklerinin içerisinde oldukça sık kullanılmaktadır. Biyometri, kişinin fizyolojik özellikleri (parmak izi, yüz tanıma vb) veya davranışları (imza, yürüyüş vb.) olarak tanımlanmaktadır (Hamdan ve Liu, 2018; Zhi ve Liu, 2019). Yaygın biyometri teknikleri parmak izi tanıma (Goljan vd., 2016), avuç izi tanıma (You vd., 2002), iris tanıma (Micheva vd., 2005), DNA (Gonzalez vd., 2009),
Yüz tanıma (Smith vd., 2015) vb. gibi farklı alanlarda kullanılmaktadır.

Yüz tanıma, yüz görüntülerinin birbirine benzerliğinden dolayı sınıflandırma işlemlerinin hassas bir şekilde yapılması gerekmektedir (Aburomman vd., 2019). Bu nedenle yüz tanıma sınıflandırmasında poz, renk, ıșık gibi etmenler doğru bir sonuç elde edebilmek için oldukça önemli etmenlerdir. $\mathrm{Bu}$ etmenlerden renk ile, farklı renk uzaylarında RGB(Red Green Blue), HSV, YUV, YCbCr, XYZ, YIQ, L*a*b*, U* $\mathrm{V}^{*} \mathrm{~W}^{*}, \mathrm{~L}^{*} \mathrm{u}^{*} \mathrm{v}^{*}, \mathrm{I}$ II2I3 ve HSI veya tek renk kullanarak yüz tanıma performansı ölçülerek değerlendirilmektedir (Shih ve Liu, 2005). Farklı renk uzayında YUV içerisinde yer alan YV, YIQ içerinde yer

\footnotetext{
* ilgili yazar / Corresponding author: bekiraksoy@isparta.edu.tr , +90-246-211-1460
} 
alan YI'nın daha iyi performans gösterdiği tespit edilmiştir (Lu vd., 2018; Shih ve Liu, 2005) Farklı poz açlarında alınan görüntülerde yüz tanıma işleminin gerçekleștirilmesi oldukça zordur. Yüz tanıma sistemindeki veri setinden, yüksek kaliteli yüz dokusuna ait eğitim verileri analiz edilerek poz normalizasyon işlemi performans iyileştirmesi gerçekleştirilmektedir (Ding ve Tao, 2017). Yüz tanıma sistemlerinde aydınlatmanın düşük olması, parlaklığın yüksek olması ve resmin çekildiği arka plan rengi gibi ışığa etki eden etmenler sınıflandırma doğruluğuna etki etmektedir (Yang vd., 2019). Bu sorunlardan, düşük aydınlatma koşulları için OTSU segmentasyon algoritması kullanılarak performans artışı gerçekleştirmiştir (Yang vd., 2019).

Yüz tanıma sistemlerinin sinıflandırılmasında sistemden alınan verileri analiz etmede genellikle derin öğrenme modelleri kullanılmaktadır. Derin öğrenme, yüksek ile düşük seviye hiyerarşinin özelliklerinin bileşimiyle oluşan öğrenme metodudur (Bengio,2019). Bu metotla yüksek seviyedeki hiyerarşik yapıda sınıflandırma, kümeleme gibi işlemler kolaylıkla gerçekleştirilmektedir. Bu üstünlüklerinden dolayı derin öğrenme tıp (Tiwari vd, 2018; Litjens vd., 2017; Gibson vd., 2018; Lundervold ve Lundervold, 2018), tarım (Zhang vd., 2019; Singh vd., 2018; Barbedo, 2018), hava araçları (Guo vd., 2018; Liu vd., 2018), șehir planlaması (Madu vd., 2017) vb. gibi alanlarda sıkça kullanılmaktadır.

Şekil 1'de gösterildiği gibi derin öğrenme çoklu sinir ağ katmanları ve bu katmanların en küçük birimi olan nöronlardan oluşur. Nöronlara gelen girdiler belli ağırlık değerleri ile çarpılıp isteğe bağlı belirlenmiş bir bias değeri ile toplanmaktadır. Diğer katmanlar içinde hesaplamalar gerçekleştirilerek son nöron katmanından sonuç değerleri alınmaktadır. Elde edilen sonuçlar ile gerçek sonuçlar kıyaslanarak hata değeri hesaplanmaktadır. Hesaplanan hata değeri kısmi türev alınıp tüm nöron katmanlarına geri yayılarak ağırlık değerleri güncellenmektedir. İstenilen hata değeri bulununcaya kadar veya belirtilen döngü sayısı kadar işlemler devam ettirilerek matematiksel bir model elde edilmektedir.

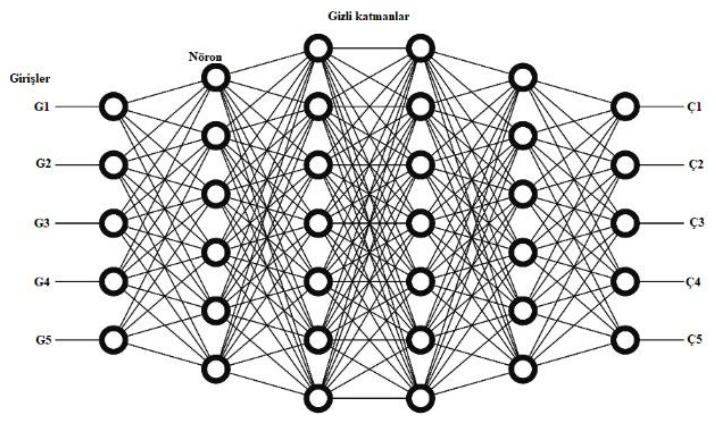

Şekil 1. Derin öğrenme yapısı

(https://medium.freecodecamp.org/want-to-knowhow-deep-learning-works-heres-a-quick-guide-foreveryone-1aedeca88076 Accessed April 24, 2019).

Son yıllarda derin öğrenme, görüntü işleme ve yüz tanıma sistemlerinde kullanılarak önemli ölçüde bașarılar elde edilmiștir (Schmidhuber, 2015; Litjens vd., 2017; Szegedy vd., 2017; Greenspan vd., 2016; Mairal vd., 2014). Yüz tanıma sistemlerinde, konvolsüyonel sinir ağı (Convolutional Neural Network CNN), çekişmeli üretici ağlar (Generative Adversarial Networks GANs) gibi derin öğrenme teknikleri veya temel bileşen analizi (Principal Component Analysis/PCA ), doğrusal diskriminant analizi (Linear Discriminant Analysis /LDA, Yerel ikili örüntü (LBP Local Binary Pattern) ve tekil değer ayrışımı (SVD singular value decomposition) gibi algoritmalar kullanılmaktadır (Parkhi vd., 2015; Shi vd., 1014; Zhang vd., 2010; Hu, 2017). Yüz tanıma sistemlerinde bu algoritmalar içerisinden performans olarak GANs algoritması ile gerçek dünya şartlarında $90 \%$ oranında doğruluk elde edilmiştir (Banerjee ve Das, 2018).

Çalışmada Isparta Uygulamalı Bilimler Üniversitesi Teknoloji Fakültesindeki gönüllü öğrenci ve öğretim üyelerinden oluşan 41 kişiye ait farklı ön, yan, üst ve alt yüz görüntüleri alınarak LDA, LBP ve PCA ile SVD algoritmaları uygulanarak üç farklı yüz tanıma modeli oluşturulmuştur. Elde edilen modeller ön, yan, üst ve alt test yüz görüntüleri üzerinde sinıflandırılılıp, RMSE ve MAPE performans ölçüt kriterlerine göre değerlendirilerek ön ve yan yüz tanıma sisteminde PCA ve SVD algoritması, üst ve alt yüz tanıma sisteminde ise LBP algoritmasinın en iyi sonucu verdiği görülmüştür.

\section{Materyal ve Yöntem}

\subsection{Materyal}

Çalışmada Isparta Uygulamalı Bilimler Üniversitesi Teknoloji Fakültesi gönüllü öğrenci ve öğretim üyelerinden oluşan 41 kişiye ait farklı pozlarda yüz görüntüleri alınarak etiketlenmiştir. Etiketlenen veriler üzerinde yüz tanıma sistemleri için kullanılan LDA, LBP ve PCA ile SVD algoritmalarının performansları değerlendirilecektir.

\subsubsection{PCA Algoritması}

PCA algoritması yüz tanıma sistemlerinde sinıflandırılmasında sıklıkla kullanılmaktadır (Oh vd., 2013). PCA algoritmasl, $M$ adet $I_{1}, I_{2}, \ldots, I_{M}$ şeklindeki yüz görüntüsünü $\mathrm{NxN}$ boyutunda vektöre dönüştürerek, denklem 1 ile görüntülerin piksellerini toplanarak ortalama değerlerden yeni bir vektör $(\Psi)$ oluşturmaktadır (Borade vd., 2016).

$\Psi=\frac{1}{M} \sum_{i=1}^{M} I_{i}$

Denklem 2' de, denklem 1'de hesaplanan vektör, tüm görüntülerden tek tek çıkartılarak yeni bir vektöre kaydedilip, denklem 1'de hesaplanan vektör ile yeni vektörün transpozu çarpılıp toplanarak, kovaryans 
matris $(C)$ elde edilmektedir (Aburomman ve Reaz, 2016).

$C=\frac{1}{M} \sum_{i=1}^{M}\left(I_{i}-\Psi\right)\left(I_{i}-\Psi\right)^{T}$

Denklem 3'de Eigen vektörleri $(V)$ ve karşılıklı Eigen değerleri $(\lambda)$ hesaplanmaktadır (Kamencay vd., 2016).

$$
C V=\lambda V
$$

Denklem 2 ve denklem 3'de Eigen vektör ve değerler büyükten küçüğe doğru sırayla kaydedilerek eğitim ve test görüntülerine benzeyen görüntüler tespit edilmektedir (Kamencay vd., 2016).

\subsubsection{LDA Algoritması}

LDA algoritması PCA algoritmasına ek olarak verilen sınıf içi dağılım matrisi ve sınıf dağılım matrisi arasında bir sınıflandırma oluşturmaktadır (Zhao vd., 1998). Denklem 4 ve denklem 5'de sınıf içi dağılım matrisi ve sınıf dağılım matrisi verilmiştir (Zainuddin ve Laswi, 2017).

$S_{W}=\sum_{j=1}^{n} \sum_{i=1}^{N_{i}} N_{i}\left(x_{i}^{j}-\Psi_{j}\right)\left(x_{i}^{j}-\Psi_{j}\right)^{T}$

$S_{b}=\sum_{i=1}^{n} N_{i}\left(\psi_{i}-\psi\right)\left(\psi_{i}-\psi\right)^{T}$

Denklem 4 ve denklem 5 verilen n, sınıf sayısını, $N_{i}$ i sınıfındaki eğitim veri sayısı, $\Psi$ ïrneğine göre vektör toplamlarının ortalamasl, $\quad \psi \quad i$ örneklerinin ortalamasını ve $x_{i}^{j}$ ise PCA'nın $i$ vektörü ve $j$ sınıfıdır (Zainuddin ve Laswi, 2017). Denklem 6'da $S_{b}$ değeri en aza ve $S_{W}$ değeri maksimuma getirilip Fisher diskriminant temel matrisinden (Z) Eigen vektörleri çıkartılarak hesaplanmaktadır (Jain vd., 2018).

$Z=S_{w}^{-1} S_{c}$

En son aşamada ise Öklid mesafesi hesaplanarak eğitim ve test görüntülerine benzeyen sınıflar tespit edilmektedir (Jain vd., 2018).

\subsubsection{LBP Algoritması}

LBP, uzamsal olarak geliştirilen bir metot vasıtasıly yüz tanıma alanında bulunan bir pozisyona yerleşerek farklı birçok yüz analiz yöntemi geliştirmek için kullanılmaktadır (Yang ve Chen, 2013). Denklem 7'da LBP algoritmasında M eleman sayısına göre minimum simetri seviyesi $\left(L_{\text {sym }}\right)$ değeri hesaplanmaktadır (Lahdenoja vd., 2005).

$$
L_{\text {sym }}=\min \left[\sum_{i=1}^{M} B(i), \sum_{i=1}^{M} \overline{B(l)}\right]
$$

Denklem 7'da B(i) LBP'nin ve komplementinin her bir ikili elemanını ifade etmektedir (Lahdenoja vd., 2005).

\subsubsection{SVD Algoritması}

SVD, sıklıkla matris işlemleriyle birlikte genellikle farklı algoritma ve metotlarla (PCA, LDA gibi) birleştirilerek yüz tanıma için kullanılan bir algoritmadır (Fronckova vd., 2018). SVD, LDA veya PCA gibi algoritmalardan elde edilen gerçek veya karmaşık bir yapıya sahip olan vektör matrisleri için kullanılmaktadır. Denklem 8'de SVD algoritmasının değer ayrışım matrisi $(M)$ değeri hesaplanmaktadır (Vinay vd., 2016).

$M=U \sum V^{*}$

Denklem 8'de $U$ birimsel matrisi, $V^{*}$ ise, eğer vektör matrisi (V) gerçek değerlerden oluşuyorsa matrisin transpozesini, karmaşık değerlerden oluşuyor ise eşlenik tranpozesi alınarak hesaplanmaktadır (Vinay vd., 2016).

\subsubsection{Yüz tanıma Algoritmaların Performans Değerlendirilmesi}

Yüz tanıma sistemlerinde kullanılan LDA, PCA algoritmaları ve CNN modellerinden elde edilen sonuçların performans değerlendirmeleri için RMSE (Root Mean Square Deviation)ve MAPE (Mean Absolute Percentage Error) kullanılmıştır. Denklem 9'de sonuçların performans değerini belirlemede kullanılacak olan RMSE yönteminin denklemi verilmiştir (Chai ve Draxler, 2014).

$R M S E=\sqrt{\frac{1}{n} \sum_{i=1}^{n} e_{i}^{2}}$

Denklem 9'da, $n$ deneysel veri sayısını, $e_{1}$ ise $i$ örneğinin hata değerini temsil etmektedir (Chai ve Draxler, 2014). Çalışmada kullanılan diğer performans değerlendirme yöntemi olan MAPE denklem 10'da verilmiștir (Kim ve Kim 2016).

$M A P E=\frac{1}{n} \sum_{t=1}^{n}\left|\frac{A_{t}-F_{t}}{A_{t}}\right|$

Denklem 10'da $n$ deneysel veri sayısını, $A_{t}$ gerçek değeri ve $F_{t}$ 'de deneysel değeri temsil etmektedir (Kim ve Kim 2016).

\subsection{Yöntem}

Çalışmada, numpy, opencv, pillow, os gibi temel Python kütüphaneleri ile PCA, LDA, SVD ve LBP algoritmaları uygulanarak en uygun yüz tanıma modeli için Şekil 2'deki gibi bir iş akış diyagramı oluşturulmuştur. 


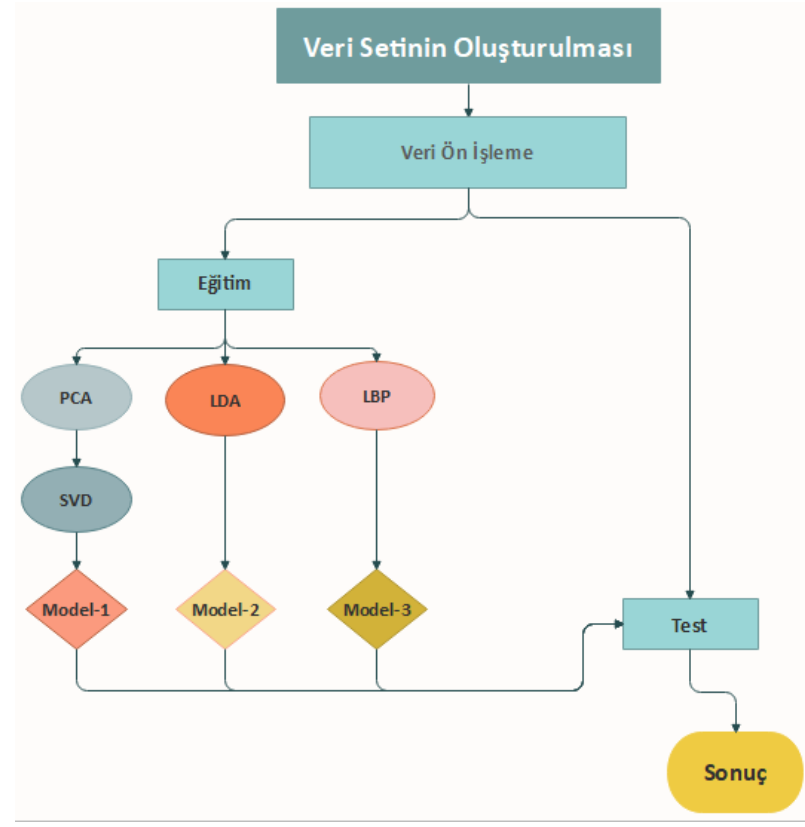

Şekil 2. İş akış diyagramı

Şekil 2'de verilen iş akış diyagramında ilk olarak 41 kişinden toplanan beş farklı yüz pozisyonu için 814 adet görüntü alınarak veri seti oluşturulmuştur. Bunun akabinde veri ön işleme aşamasına geçilmiştir. Veri ön işlemede, ilk olarak elde edilen resimlerin boyutları çok büyük olduğundan olușturulacak modelde görüntü analizleri hızlı bir şekilde gerçekleştirilebilmesi için Python programlama dilindeki pillow ve os kütüphaneleri kullanılarak hazırlanacak bir program ile görüntülerin boyutları küçültülecektir. Veri ön işlemenin ikinci aşamasında ise küçültülen görüntüler üzerinde haar cascade yöntemi kullanılarak görüntülerin yüz görüntüsü olup olmadığı tespit edilmeye çalışılıp yüz görüntüsü olmayan görüntüler veri setinden çıkarılacaktır. Üçüncü aşamada ise hazırlanan veri setindeki görüntülerin $\% 75$ 'i eğitim, $\% 25$ ise test görüntüsü olarak ayrılacaktır. Eğitim veri seti üzerinde üç farklı yöntem için Python programlama dilinde hazırlanacak programlar ile üç farkl model elde edilmeye çalıșllacaktır. İlk yöntemde numpy kütüphanesi kullanılarak PCA ve SVD algoritmaları birlikte kullanılarak ilk model elde edilecektir. İkinci ve üçüncü yöntemde ise opencv kütüphanesi kullanılarak LDA ve LBP algoritmalarının modelleri elde edilecektir. Elde edilen modeller test verileri üzerinde test edilerek en uygun sonuçlar RMSE ve MAPE ile ile değerlendirilerek en uygun sonuç veren model belirlenecektir.

\section{Araştırma Bulguları}

Çalışmada, 41 kişiden alınan 2594x1944 piksel boyutunda 814 adet yüz görüntüsünün büyüklüğü 11.4 GB ve ortalama bir resmin büyüklüğü ise yaklaşık olarak 14. $34 \mathrm{MB}$ olarak tespit edilmiştir. Bu büyüklükteki yüz görüntüleri üzerinde analiz yapmanın zorluğundan dolayı görüntü boyutlarını küçültmek için hazırlanmış program ile her bir yüz görüntüsü 500x375 piksel boyutuna düşürülerek yüz görüntü dosyasının boyutu 549 KB düşürülerek yüz tanıma analizlerinde zaman açısından kazanç sağlanmıștır. Veri ön ișleme ikinci așamasında haar cascade sınıflandırıcısı kullanılarak, boyutu düșürülen yüz görüntülerin içerisinde yüz görüntüsü olmayan görüntüler veri setinden çıkarılarak yüz tanıma sisteminde oluşturulacak model için hatalı veri gelme durumu önlenmiștir.

Görüntülerin \%75 eğitim ve \%25 test görüntüsü olarak ayrılmıştır. İlk olarak 41 farklı sınıf için ön, yan, üst ve alt eğitim yüz görüntülerinden PCA ve SVD algoritmaları kullanılarak bir model elde edilmiștir. Elde edilen model test yüz görüntüleri üzerinde sınıflandırılarak ön yüz görüntülerinde MAPE'ye göre doğruluk oranı \%97.53 RMSE'ye göre hata değeri 0.156 olarak tespit edilmiștir. Bulunan hata değerine göre, RMSE'nin göre doğruluk oranını \%84,4 olarak bulunmuştur. Yan yüz görüntülerinde MAPE'ye göre $\% 5,4$ RMSE'nin hata değeri ise 0.9745 olarak tespit edilmiştir. Bulunan hata değerine göre RMSE'nin doğruluk oranı \%2.5 olarak bulunmuştur. Üst ve alt görüntülerde ise MAPE'ye göre doğruluk oranı \%20.95, RMSE'nin hata değeri 0.883 olarak tespit edilmiștir. RMSE'nin doğruluk oranı göre \%11.7 olarak bulunmuştur. Tablo 1'de ilk beş sınıf örnek olarak verilmiştir.

Tablo 1. PCA ve SVD algoritmaları ile yüz tanıma sistemi sınıflandırma örneği

\begin{tabular}{|l|l|l|l|}
\hline \multirow{2}{*}{ Sinıf_ID } & \multicolumn{3}{|c|}{ Görüntü Tespiti } \\
\cline { 2 - 4 } & Ön & Yan & Üst ve Alt \\
\hline 1 & Doğru & Yok & Doğru \\
\hline 2 & Doğru & Yok & Yanlış \\
\hline 3 & Doğru & Doğru & Yanlış \\
\hline 4 & Doğru & Yok & Doğru \\
\hline 5 & Doğru & Yok & Yok \\
\hline
\end{tabular}

PCA ve SVD algoritmalarıyla elde edilen modelde, yüz tanıma sisteminin ön yüz görüntülerindeki tespit doğruluk oranı yüksek iken yan, üst ve alt yüz görüntülerinde ise düșük olduğu tespit edilmiștir.

İkinci model olarak aynı veri seti üzerinde LDA algoritması uygulanarak bir model oluşturulmuştur. Elde edilen model test yüz görüntüleri üzerinde sınıflandırılarak ön yüz görüntülerinde MAPE'ye göre doğruluk oranı \%70.73 RMSE'ye göre hata değeri 0.541 olarak tespit edilmiştir. Bulunan hata değerine göre, RMSE'nin göre doğruluk oranını \%45.9 olarak bulunmuştur. Yan yüz görüntülerinde MAPE'ye göre doğruluk oranı \%0 RMSE'ye göre hata değeri 0 olarak tespit edilmiştir. Bulunan hata değerine göre, RMSE'nin göre doğruluk oranını \%0 olarak bulunmuştur. Üst ve alt görüntülerde ise MAPE'ye göre doğruluk oranı \%26.83 RMSE'ye göre hata değeri 0.855 olarak tespit edilmiștir. Bulunan hata değerine göre, RMSE'nin göre doğruluk oranını \%14.5 olarak 
bulunmuştur. Tablo 2'de ilk beş sınıf örnek olarak verilmiştir.

Tablo 2. LDA algoritması ile yüz tanıma sistemi sinıflandırma örneği

\begin{tabular}{|l|l|l|l|}
\hline \multirow{2}{*}{ Sinıf_ID } & \multicolumn{3}{|c|}{ Görüntü Tespiti } \\
\cline { 2 - 4 } & Ön & Yan & Üst ve Alt \\
\hline 1 & Doğru & Yok & Yanlıș \\
\hline 2 & Doğru & Yok & Yanlıș \\
\hline 3 & Doğru & Yok & Doğru \\
\hline 4 & Doğru & Yok & Yanlıș \\
\hline 5 & Doğru & Yok & Yok \\
\hline
\end{tabular}

LDA algoritmasıyla elde edilen modelde, yüz tanıma sisteminin ön yüz görüntülerindeki tespit doğruluk oranı yüksek iken yan, üst ve alt yüz görüntülerinde ise başarısız olduğu görülmüştür.

Çalışmada son model olarak aynı veri seti üzerinde LBP algoritması uygulanarak bir model oluşturulmuştur. Elde edilen model test yüz görüntüleri üzerinde sinıflandırılarak ön yüz görüntülerinde MAPE'ye göre doğruluk oranı \%80.5 RMSE'ye göre hata değeri 0.442 olarak tespit edilmiştir. Bulunan hata değerine göre, RMSE'nin göre doğruluk oranını \%55.8 olarak bulunmuștur. Yan yüz görüntülerinde MAPE'ye göre doğruluk oranı $\% 0$ RMSE'ye göre hata değeri 0 olarak tespit edilmiştir. Bulunan hata değerine göre, RMSE'nin göre doğruluk oranını $\% 0$ olarak bulunmuștur. Üst ve alt görüntülerde ise MAPE'ye göre doğruluk oranı \%39.02 RMSE'ye göre hata değeri 0.781 olarak tespit edilmiştir. Bulunan hata değerine göre, RMSE'nin göre doğruluk oranını \%21.9 olarak bulunmuştur. Tablo 3'de ilk beş sınıf örnek olarak verilmiştir.

Tablo 3. LBP algoritması ile yüz tanıma sistemi sınıflandırma örneği

\begin{tabular}{|l|l|l|l|}
\hline \multirow{2}{*}{ Sinıf_ID } & \multicolumn{3}{|c|}{ Görüntü Tespiti } \\
\cline { 2 - 4 } & Ön & Yan & Üst ve Alt \\
\hline 1 & Doğru & Yok & Yanlıș \\
\hline 2 & Doğru & Yok & Yanlıș \\
\hline 3 & Doğru & Doğru & Yanlıș \\
\hline 4 & Doğru & Yok & Yanlıș \\
\hline 5 & Doğru & Yok & Yok \\
\hline
\end{tabular}

LBP algoritmasıyla elde edilen modelde, yüz tanıma sisteminin ön yüz görüntülerindeki tespit doğruluk oranı yüksek iken yan, üst ve alt yüz görüntülerinde ise başarısız olduğu görülmüştür.

Tablo 4'de oluşturulan üç modelin yüz tanıma performans değerleri verilmiştir.
Tablo 4. Yüz tanıma algoritmalarının performans değerlendirme sonuçları

\begin{tabular}{|l|l|l|l|l|}
\hline $\begin{array}{l}\text { Performans } \\
\text { Değerlendirme } \\
\text { Ölçütü }\end{array}$ & \multirow{2}{*}{$\begin{array}{l}\text { Yüz Tanıma } \\
\text { Algoritmaları }\end{array}$} & \multicolumn{3}{|l|}{ Görüntü Tespit Yönü } \\
\cline { 3 - 5 } & & Ön & Yan & $\begin{array}{l}\text { Alt } \\
\text { ve } \\
\text { Üst }\end{array}$ \\
\hline \multirow{3}{*}{$R^{2}$} & & & & 0.883 \\
\hline \multirow{3}{*}{ MAPE(\%) } & PCA ve SVD & 0.156 & 0.975 & 0.541 \\
\cline { 2 - 5 } & LDA & 0.541 & 0 & 0.855 \\
\cline { 2 - 5 } & LBP & 0.442 & 0 & 0.781 \\
\cline { 2 - 5 } & PCA ve SVD & 97.531 & 5.4 & 20.95 \\
\cline { 2 - 5 } & LDA & 70.73 & 0 & 26.83 \\
\cline { 2 - 5 } & LBP & 80.50 & 0 & 39.02 \\
\hline
\end{tabular}

Tablo 4'de görüldüğü gibi yüz tanıma sistemlerinde ön yüz görüntülerinde RMSE'ye göre PCA ve SVD algoritması, MAPE'ye göre ise PCA ve SVD algoritması, yan yüz görüntülerinde RMSE'ye göre PCA ve SVD algoritması, MAPE'ye göre ise PCA ve SVD algoritması ve alt ve üst yüz görüntülerinde RMSE'ye göre LBP algoritması, MAPE'ye göre ise LBP algoritmasının başarılı olduğu görülmektedir.

\section{Sonuç ve Tartışma}

Günümüzde teknolojideki gelişmesi ile birlikte güvenlik sistemlerinin önemi de artmıştır. Güvenlik sistemleri içerisinde parmak izi, yüz tanıma gibi sistemler büyük önem taşımaktadır. Çalışmada 41 farklı kişiye ait yüz, ön, yan, alt ve üst yüz görüntüleri alınarak, yüz görüntülerin boyutları yüz tanıma analizlerinin hızını attırmak için küçültülmüştür. Küçültme işleminden sonra yüz görüntüleri haar cascade sınıflandırıcısı kullanılarak yüz görüntüsü olup olmadı̆̆ı tespit edilerek, yüz olmayan görüntüler veri setinden çıkarılmıştır. Görüntüler \%75 eğitim ve \%25 test verisi olmak üzere ayrılarak LDA, LBP, PCA ile SVD algoritmaları uygulanarak yüz tanıma modeller RMSE ve MAPE performans değerlendirme kriterlerine göre değerlendirilip sonuçlar aşağıda verilmiştir.

- Ön yüz görüntülerinde hem RMSE hem de MAPE performans değerlendirme ölçütüne göre PCA ve SVD algoritmasının en doğru sonucu verdiği tespit edilmiştir.

- Yan yüz görüntülerinde hem RMSE hem de MAPE performans değerlendirme ölçütüne göre PCA ve SVD algoritmasının en doğru sonucu verdiği tespit edilmiştir.

- Üst ve alt yüz görüntülerinde hem RMSE hem de MAPE performans değerlendirme ölçütüne göre LBP algoritmasının en doğru sonucu verdiği tespit edilmiştir.

Yapılacak farklı çalışmalarda, yüz tanıma sistemlerindeki doğruluk oranı CNN, GANs gibi derin öğrenme modelleri kullanılarak arttırabileceği düşünülmektedir. 


\section{Conflict of Interest / Çıkar Çatışması}

Yazar tarafından herhangi bir çıkar çatışması beyan edilmemiştir.

No conflict of interest was declared by the author.

\section{Kaynaklar}

Abudarham, N., Shkiller, L., \& Yovel, G., 2019. Critical features for face recognition. Cognition, 182, 73-83. https://doi.org/10.1016/j.cognition.2018.09.002.

Aburomman, A. A., \& Reaz, M. B. I., 2016. Ensemble of binary SVM classifiers based on PCA and LDA feature extraction for intrusion detection. In 2016 IEEE Advanced Information Management, Communicates, Electronic and Automation Control Conference (IMCEC), 636-640, IEEE. DOI: 10.1109/IMCEC.2016.7867287

Banerjee, S., \& Das, S., 2018. LR-GAN for degraded Face Recognition. Pattern Recognition Letters, 116, 246-253. https://doi.org/10.1016/j.patrec. 2018. 10.034

Barbedo, J. G. A., 2018. Impact of dataset size and variety on the effectiveness of deep learning and transfer learning for plant disease classification. Computers and Electronics in Agriculture, 153, 4653. https://doi.org/10.1016/ j.compag. 2018. 08.013

Becerra-Riera, F., Morales-González, A., \& MéndezVázquez, H., 2018. Facial marks for improving face recognition. Pattern Recognition Letters, 113, 3-9. https://doi.org/10.1016/j.patrec. 2017. 05. 005.

Bengio, Y., 2009. Learning deep architectures for AI. Foundations and trends in Machine Learning, 2(1), $1-127$.

Borade, S. N., Deshmukh, R. R., \& Ramu, S., 2016. Face recognition using fusion of PCA and LDA: Borda count approach. In 2016 24th Mediterranean conference on control and automation (MED) 1164-1167, IEEE.

Chai, T., \& Draxler, R. R. (2014). Root mean square error (RMSE) or mean absolute error (MAE)?Arguments against avoiding RMSE in the literature. Geoscientific model development, 7(3), 12471250 .

Ding, C., \& Tao, D., 2017. Pose-invariant face recognition with homography-based normalization. Pattern Recognition, 66, 144-152. https://doi.org/10.1016/j.patcog.2016.11.024

Fronckova, K., Prazak, P., \& Slaby, A., 2018. Singular Value Decomposition and Principal Component
Analysis in Face Images Recognition and FSVDR of Faces. In International Conference on Information Systems Architecture and Technology, 105-114. Springer, Cham.

Gibson, E., Li, W., Sudre, C., Fidon, L., Shakir, D. I., Wang, G., ... \& Whyntie, T., 2018. NiftyNet: a deep-learning platform for medical imaging. Computer methods and programs in biomedicine, 158, 113-122.

Greenspan, H., Van Ginneken, B., \& Summers, R. M., 2016. Guest editorial deep learning in medical imaging: Overview and future promise of an exciting new technique. IEEE Transactions on Medical Imaging, 35(5), 1153-1159. https://doi.org/10.1109/TMI.2016.2553401.

Goljan, M., Chen, M., Comesaña, P., \& Fridrich, J., 2016. Effect of compression on sensor-fingerprint based camera identification. Electronic Imaging, 2016(8), 1-10. https://doi.org/10.2352/ISSN.2470-1173. 2016.8.MWSF-086.

Gonzalez, M. A., Baraloto, C., Engel, J., Mori, S. A., Pétronelli, P., Riéra, B., ... \& Chave, J., 2009. Identification of Amazonian trees with DNA barcodes. PLoS one, 4(10), e7483. https://doi.org/10.1371/journal.pone.0007483

Guo, D., Zhong, M., Ji, H., Liu, Y., \& Yang, R., 2018. A hybrid feature model and deep learning based fault diagnosis for unmanned aerial vehicle sensors. Neurocomputing, 319, 155-163.

Hamdan, B., \& Mokhtar, K., 2018. Face recognition using angular radial transform. Journal of King Saud University-Computer and Information Sciences, 30(2), 141-151. https://doi.org/ 10. 1016/ j.jksuci.2016.10.006.

https://medium.freecodecamp.org/want-to-knowhow-deep-learning-works-heres-a-quick-guidefor-everyone-1aedeca88076 Accessed April 24, 2019.

Hu, J., 2017. Discriminative transfer learning with sparsity regularization for single-sample face recognition. Image and vision computing, 60, 4857.

Jain, U., Choudhary, K., Gupta, S., \& Privadarsini, M. J. P., 2018. Analysis of Face Detection and Recognition Algorithms Using Viola Jones Algorithm with PCA and LDA. In 2018 2nd International Conference on Trends in Electronics and Informatics (ICOEI), 945-950. IEEE. doi: 10.1109/ICOEI.2018.8553811

Kamencay, P., Trnovszky, T., Benco, M., Hudec, R., Sykora, P., \& Satnik, A., 2016. Accurate wild animal recognition using PCA, LDA and LBPH, 62-67, IEEE. DOI: 10.1109/ELEKTRO.2016.7512036 
Kim, S., \& Kim, H., 2016. A new metric of absolute percentage error for intermittent demand forecasts. International Journal of Forecasting, 32(3), 669-679. https://doi.org/10.1016/ j.ijforecast.2015.12.003

Lahdenoja, O., Laiho, M., \& Paasio, A., 2005. Reducing the feature vector length in local binary pattern based face recognition. In IEEE International Conference on Image Processing 2005, 2, II-914. IEEE.

Litjens, G., Kooi, T., Bejnordi, B. E., Setio, A. A. A., Ciompi, F., Ghafoorian, M., ... \& Sánchez, C. I. 2017. A survey on deep learning in medical image analysis. Medical image analysis, 42, 60-88. https://doi.org/10.1016/j.media.2017.07.005.

Liu, Y., Wang, H., Su, Z., \& Fan, J., 2018. Deep learning based trajectory optimization for UAV aerial refueling docking under bow wave. Aerospace Science and Technology, 80, 392-402.

Lu, Z., Jiang, X., \& Kot, A., 2018. Color Space Construction by Optimizing Luminance and Chrominance Components for Face Recognition. Pattern Recognition. https://doi.org/10.1016/ j. patcog.2018.06.015

Lundervold, A. S., \& Lundervold, A., 2018. An overview of deep learning in medical imaging focusing on MRI. Zeitschrift für Medizinische Physik, 29,102127. https://doi.org/10.1016/ j.zemedi. 2018. 11. 002.

Madu, C. N., Kuei, C. H., \& Lee, P., 2017. Urban sustainability management: A deep learning perspective. Sustainable cities and society, 30, 117.

Mairal, J., Bach, F., \& Ponce, J., 2014. Sparse modeling for image and vision processing. Foundations and Trends $®$ in Computer Graphics and Vision, 8(2-3), 85-283. http://dx.doi.org/10.1561/0600000058.

Micheva, I., Ziros, P., Pherson, L., Giannakoulas, N., Symeonidis, A., \& Zoumbos, N., 2005. Involvement of ERK, p38 and NFKB Signalling in the Maturation Defects of Monocyte Derived Dendritic Cells in Patients with Myelodysplastic Syndrome. https://doi.org/10.5272/jimab.2014206.542

Oh, S. K., Yoo, S. H., \& Pedrycz, W., 2013. Design of face recognition algorithm using PCA-LDA combined for hybrid data pre-processing and polynomialbased RBF neural networks: Design and its application. Expert Systems with Applications, 40(5), 1451-1466. https://doi.org/10.1016/ j.eswa.2012.08.046.
Parkhi, O. M., Vedaldi, A., \& Zisserman, A., 2015. Deep face recognition. In BMVC 1(3),6.

Schmidhuber, J., 2015. Deep learning in neural networks: An overview. Neural networks, 61, 85 117. https://doi.org/10.1016/j.neunet. 2014.09. 003

Shi, X., Yang, Y., Guo, Z., \& Lai, Z., 2014. Face recognition by sparse discriminant analysis via joint L2, 1norm minimization. Pattern Recognition, 47(7), 2447-2453. https://doi.org/10.1016/j.patcog. 2014.01.007

Shih, P., \& Liu, C., 2005. Comparative assessment of content-based face image retrieval in different color spaces. International Journal of Pattern Recognition and Artificial Intelligence, 19(07), 873-893. https://doi.org/10.1142/ S0218001405004381

Singh, A. K., Ganapathysubramanian, B., Sarkar, S., \& Singh, A., 2018. Deep learning for plant stress phenotyping: trends and future perspectives. Trends in plant science, 23, 883-898. https://doi.org/10.1016/j.tplants.2018.07.004.

Smith, D. F., Wiliem, A., \& Lovell, B. C., 2015. Face recognition on consumer devices: Reflections on replay attacks. IEEE Transactions on Information Forensics and Security, 10(4), 736-745.

Szegedy, C., Ioffe, S., Vanhoucke, V., \& Alemi, A. A., 2017. Inception-v4, inception-resnet and the impact of residual connections on learning. In AAAI $4,4278-4284$

Tiwari, P., Qian, J., Li, Q., Wang, B., Gupta, D., Khanna, A., ... \& de Albuquerque, V. H. C., 2018. Detection of subtype blood cells using deep learning. Cognitive Systems Research, 52, 1036-1044.

Vinay, A., Vasuki, V., Bhat, S., Jayanth, K. S., Murthy, K. B., \& Natarajan, S., 2016. Two dimensionality reduction techniques for surf based face recognition. Procedia Computer Science, 85, 241248.

Yang, A., Wang, Q., \& Cao, J., 2019. Research on Adaptive Face Recognition Algorithm Under Low Illumination Condition. In Advances in Graphic Communication, Printing and Packaging(pp. 266272). Springer, Singapore. https://doi.org /10.1007/978-981 -13-3663-8_37

Yang, B., \& Chen, S., 2013. A comparative study on local binary pattern (LBP) based face recognition: LBP histogram versus LBP image. Neurocomputing, 120, 365-379. 
You, J., Li, W., \& Zhang, D., 2002. Hierarchical palmprint identification via multiple feature extraction. Pattern recognition, 35(4), 847-859. https://doi.org/10.1016/S0031-3203(01)001005

Zainuddin, Z., \& Laswi, A. S., 2017. Implementation of the LDA algorithm for online validation Based on face recognition. In Journal of Physics: Conference Series, 801 (1), 12-47). IOP Publishing. doi:10.1088/1742-6596/801/1/012047.

Zhang, B., Gao, Y., Zhao, S., \& Liu, J., 2019. Local derivative pattern versus local binary pattern: face recognition with high-order local pattern descriptor. IEEE transactions on image processing, 19(2), 533-544.

Zhang, B., Gao, Y., Zhao, S., \& Liu, J., 2010. Local derivative pattern versus local binary pattern: face recognition with high-order local pattern descriptor. IEEE transactions on image processing, 19(2), 533-544.

Zhao, W., Krishnaswamy, A., Chellappa, R., Swets, D. L., \& Weng, J., 1998. Discriminant analysis of principal components for face recognition. In Face Recognition,73-85, Springer, Berlin, Heidelberg.

Zhi, H., \& Liu, S., 2019. Face recognition based on genetic algorithm. Journal of Visual Communication and Image Representation, 58, 495-502. https://doi.org/10.1016/ j.jvcir. 2018. 12.012 .

Zhong, L., Hu, L., \& Zhou, H., 2019. Deep learning based multi-temporal crop classification. Remote Sensing of Environment, 221, 430-443. 